\title{
EDITORIAL
}

\section{Broadening the Branches and Deepening the Roots of Transnational Environmental Law}

\section{INTRODUCTION}

The year 2020 has been one of extraordinary tumult and change. At the beginning of the year, few could have predicted how the COVID-19 pandemic would so radically pervade every aspect of human lives and livelihoods, with profound implications for how people live, love, move, work, and connect in our societies. ${ }^{1}$ The pandemic has also vividly illustrated our global interconnectedness, as well as the ways in which an initially localized problem can come to transcend international boundaries, with national, provincial, and local implications. The various environmental challenges examined in this issue - from climate change to biodiversity to persistent organic pollutants - are similarly cross-sectional in nature and effect. For example, like the COVID-19 pandemic, climate change is recognized as a truly global problem, yet one with myriad distinctive impacts and policy responses in different regions, countries, and localities. $^{2}$

The systemic nature and impacts of environmental problems are some of the features of environmental research that prompted the development of the new discipline of transnational environmental law. ${ }^{3}$ Research in this area simultaneously requires a broader lens to take into account many different branches of law and policy, and a deepening of study to understand how problems manifest at multiple levels of governance. It is a mission to which this journal, as it enters its tenth cycle, is fully dedicated. Indeed, all contributors to this issue in their respective articles provide evidence of this simultaneous broadening and deepening in their exploration of the diverse compartments that make up the wider ecosystem of the study of transnational environmental law.

1 R. Moore et al., 'Life after Covid: Will Our World Ever Be the Same', The Guardian, 29 Nov. 2020, available at: https://www.theguardian.com/world/2020/nov/29/life-after-covid-will-our-world-ever-be-thesame.

2 See, e.g., Intergovernmental Panel on Climate Change (IPCC) (V. Masson-Delmotte et al. (eds)), Global Warming of $1.5^{\circ} \mathrm{C}$ : An IPCC Special Report on the Impacts of Global Warming of $1.5^{\circ} \mathrm{C}$ Above Pre-Industrial Levels and Related Global Greenhouse Gas Emission Pathways, in the Context of Strengthening the Global Response to the Threat of Climate Change, Sustainable Development, and Efforts to Eradicate Poverty (IPCC, 2019).

3 V. Heyvaert \& T.F.M. Etty, 'Introducing Transnational Environmental Law' (2012) 1(1) Transnational Environmental Law, pp. 1-11; V. Heyvaert \& L. Duvic-Paoli (eds), Research Handbook on Transnational Environmental Law (Edward Elgar, 2020). 
In this issue of Transnational Environmental Law (TEL), topics traversed include climate change displacement, China's state-centric approach to corporate social responsibility, transnational infrastructure projects and the frictions they create, community governance in underwater cultural heritage protection, the ecosystem approach in environmental law, and the regulation of hazardous substances. Each author offers us a perspective on broader questions in the field, such as the standing and relevance of the ecosystem approach ${ }^{4}$ or the role of community in environmental governance, ${ }^{5}$ while also providing a depth of insight, often through the use of diverse case studies.

2. DEEPENING THE ROOTS:

\section{ANALYZING SITES OF CONTESTATION}

A particularly fruitful way in which transnational environmental law scholarship can add depth to our knowledge and understanding of environmental problems is by analyzing particular sites of actual and potential contestation in environmental law. The articles by Fanny Thornton, Sanja Bogojević and Mimi Zou, and Bingyu Liu illustrate this framing.

Fanny Thornton's piece 'Of Harm, Culprits and Rectification: Obtaining Corrective Justice for Climate Change Displacement ${ }^{6}$ delves into the contested space that sits at the nexus of debates about climate justice and climate displacement. Climate change displacement evokes, at least in some circumstances, a sense of injustice. As Thornton puts it, these scenarios 'concern the loss of both tangible and intangible things that many people value - most basically an inhabitable home and community, an ongoing livelihood base, a sense of personal security, an intimate connection with a place-based history, and so on' and, importantly, 'these experiences of loss arise not by accident but from the actions of others who have not infrequently enjoyed the benefits that derive from these actions'? Using the lens of 'corrective justice', Thornton examines how those facing the effects of climate change displacement can pursue, and are pursuing, avenues for rectification.

For some, what is important is that culprits are held responsible for climate change harm, including displacement (the 'ethicist approach' to corrective justice). ${ }^{8}$ Pertinent examples in this regard include the claim by Peruvian farmer Saúl Luciano Lliuya against German energy producer RWE, the investigation by the Philippine

4 G. Futhazar, 'The Normative Nature of the Ecosystem Approach: A Mediterranean Case Study' (2021) 10(1) Transnational Environmental Law, pp. 109-33; J. Razzaque \& C. Lester, 'Why Protect Ancient Woodland in the UK? Rethinking the Ecosystem Approach' (2021) 10(1) Transnational Environmental Law, pp. 135-58.

5 J.B. Martin, 'Harnessing Local and Transnational Communities in the Global Protection of Underwater Cultural Heritage' (2021) 10(1) Transnational Environmental Law, pp. 85-108.

6 F. Thornton, 'Of Harm, Culprits and Rectification: Obtaining Corrective Justice for Climate Change Displacement' (2021) 10(1) Transnational Environmental Law, pp. 13-33.

7 Ibid., p. 18.

8 Ibid., p. 20. 
Commission on Human Rights into the human rights responsibilities of carbon majors, and the claim by a group of Torres Strait Islanders against the Australian government for failure to take action on climate change. ${ }^{9}$ For others, identifying the 'culprit' of climate harm matters less than achieving rectification or reversal of the harm itself (the 'instrumentalist approach' to corrective justice). ${ }^{10}$ Examples that Thornton discusses here span from the Warsaw International Mechanism for Loss and Damage Associated with Climate Change Impacts ${ }^{11}$ and dedicated provisions of the Paris Agreement $^{12}$ for loss and damage, to the climate finance architecture set up to provide funding that addresses climate change harm in developing countries. ${ }^{13}$

Thornton's 'corrective justice' approach to analyzing these examples sheds light on other recent developments involving redress for climate change displacement (and potentially other climate injustices) and also facilitates exploration of ongoing challenges in this domain, as Thornton touches on in her piece. ${ }^{14}$ These include difficult questions in climate litigation and rectification claims about what 'harm' means and how it can be quantified, how causation can be established between the actions of some and the harm suffered by others, and how redress mechanisms can be enforced and against whom. As Thornton argues, with an increasing number of people and communities facing a future where they 'cannot stay put in the face of climate change', justice-based discourses, and especially corrective justice perspectives, must join others in conceptualizing solutions for the climate displaced. ${ }^{15}$

Thornton focuses on people affected by climate change and their avenues for redress. In their contribution on "Making Infrastructure "Visible" in Environmental Law: The Belt and Road Initiative and Climate Change Friction', ${ }^{16}$ Sanja Bogojević and Mimi Zou, too, direct their attention to 'frictions' or disputes that emerge in local communities. In particular, they focus on the tensions that have become apparent through climate change-related disputes arising from China's Belt and Road Initiative (BRI) projects in Kenya and Pakistan. ${ }^{17}$ The authors' aim is both to make infrastructure projects, and the contestation that they create in local contexts, more visible in environmental law, ${ }^{18}$ and to show that law provides an important 'stabilizing' mechanism for such friction. $^{19}$

\footnotetext{
9 Ibid., pp. 26-30.

10 Ibid., p. 20.

11 Decision 2/CP.19, 'Warsaw International Mechanism for Loss and Damage Associated with Climate Change Impacts' (11-23 Nov. 2013), UN Doc. FCCC/CP/2013/10/Add.1.

12 Paris (France), 12 Dec. 2015, in force 4 Nov. 2016 available at: http://unfccc.int/paris_agreement/items/ 9485.php.

13 Thornton, n. 6 above, pp. 30-2.

14 Ibid., pp. 21-5.

15 Ibid., p. 32.

16 S. Bogojevič \& M. Zou, 'Making Infrastructure "Visible" in Environmental Law: The Belt and Road Initiative and Climate Change Friction' (2021) 10(1) Transnational Environmental Law, pp. 35-56.

17 Ibid., p. 37.

18 Ibid., p. 36.

19 Ibid., p. 38.
} 
Bogojevic and Zou start with the premise that infrastructure, defined as 'a variety of networks used to provide services and facilitate communication and connections that are essential for the operation of societies and enterprises', ${ }^{20}$ is seen largely in a positive light at a macro level, especially in terms of its role in promoting global connectivity. Indeed, the idea of 'promoting global connectivity' is essential for the conceptualization of the BRI. ${ }^{21}$ More recently, the BRI has employed the use of a 'green development' narrative to portray its infrastructure projects. ${ }^{22}$ However, as Bogojevic and Zou highlight, these broader 'global' and 'green' narratives render invisible the frictions created by infrastructure in local contexts. ${ }^{23}$ It is climate change, the authors contend, that has the potential to create these large-scale but localized frictions under the BRI. ${ }^{24}$ Using the case studies of $L a m u^{25}$ - the community-led challenge to the environmental impact assessment for Kenya's first coal-fired power station decided by the Kenyan National Environmental Tribunal - and Ali v. Pakistan ${ }^{26}$ - a seven-year old's legal challenge to the coal-field development and construction of plants in Pakistan currently pending before the Supreme Court - Bogojevic and Zou provide an in-depth analysis of how BRI-related infrastructure causes climate change-related friction in local communities. $^{27}$

Environmental law, in these circumstances, provides a forum through which 'such disputes are vocalized and eventually stabilized through adjudication'. ${ }^{28}$ While the authors express uncertainty as to whether adjudication by courts will contribute to a long-term 'greening' of BRI projects, they suggest that adjudication 'offers a muchneeded platform where local and global infrastructure-related visions and concerns can be vocalized and potentially resolved'. ${ }^{29}$ Domestic court challenges to coal-related BRI infrastructure potentially provide a new avenue for transnational climate litigation as this begins to emerge in the global south. ${ }^{30}$

While Bogojević and Zou qualify their analysis by noting the modest size of their case study sample, their contribution lies in depth of analysis and nuance. The observation of Bent Flyvbjerg, albeit in the context of social science but equally applicable to law, is pertinent here: 'The advantage of large samples is breadth, while their

\footnotetext{
20 Ibid., p. 39.

21 Ibid.

22 Ibid., pp. 43-4.

23 Ibid., pp. 42, 45.

24 Ibid., p. 45.

25 Save Lamu \& Others v. National Environmental Management Authority and Amu Power Co. Ltd, National Environmental Tribunal, NET 196 of 2016, Decision of 26 July 2019 (Kenya).

26 Ali v. Federation of Pakistan (2016), pending before the Supreme Court of Pakistan, petition available at: http://climatecasechart.com/non-us-case/ali-v-federation-of-pakistan-2/?cn-reloaded=1.

27 Bogojevič \& Zou, n. 16 above, pp. 49-53.

28 Ibid., p. 4.

29 Ibid., pp. 54-5.

30 J. Peel \& J. Lin, 'Transnational Climate Litigation: The Contribution of the Global South' (2019) 113(4) American Journal of International Law, pp. 679-726; J. Setzer \& L. Benjamin, 'Climate Litigation in the Global South: Constraints and Innovations’ (2020) 9(1) Transnational Environmental Law, pp. 77-101.
} 
problem is one of depth. For the case study, the situation is the reverse. Both approaches are necessary for a sound development of social science'. 31

Bingyu Liu's contribution, 'China's State-Centric Approach to Corporate Social Responsibility Overseas: A Case Study in Africa', ${ }^{32}$ aptly demonstrates the value that an in-depth case analysis brings to studies in transnational environmental law. Liu examines a single instance of BRI investment in Kenya to analyze the Chinese government's approach to corporate social responsibility (CSR) in its developments overseas. Filling a gap in existing research on CSR in China - literature which to date has focused on CSR in domestic practices - Liu examines the strengths and weaknesses of China's state-led approach in its investments overseas under the BRI, and specifically in Africa. ${ }^{33}$

Liu finds that, while state-led approaches to CSR may enhance compliance, implementation and enforcement of CSR initiatives (compared with the more questionable compliance-pull of corporate voluntarism), a state-centric CSR approach comes with important limitations. ${ }^{34}$ Most notably, its efficacy is contingent on the continued motivation and involvement of the Chinese government, with ancillary concerns regarding its lack of accountability and transparency and the presence of competing environmental or economic priorities within the Chinese government. Moreover, state-led approaches constrain the role for civil society organizations and companies themselves in CSR. ${ }^{35}$

Following the broader assessment of China's state-centric approach to CSR, Liu's analysis is given depth through her examination of the Standard Gauge Railway (SGR) in Kenya, a railway construction project undertaken by the China Road and Bridge Corporation (CRBC), a Chinese state-owned company. The Chinese government - operating through channels which include the Chinese embassy, China Exim Bank, and high-level political visits - played an important direct governance oversight role towards the CRBC, ensuring the sustainable construction of the SGR. ${ }^{36}$ Liu illustrates how the limitations of a state-centric approach to CSR were made manifest in this case study. She highlights that the Kenyan project 'developed in isolation from the local NGOs and media, does not encourage its CSR strategies to be responsive to local needs' ${ }^{37}$ The success of the project was dependent on the political commitment of the Chinese government to embed sustainability considerations and, overall, the project suffered from a lack of transparency. ${ }^{38}$

31 B. Flyvbjerg, 'Five Misunderstandings About Case-Study Research' (2006) 12(2) Qualitative Inquiry, pp. 219-45, at 271 .

32 B. Liu, 'China's State-Centric Approach to Corporate Social Responsibility Overseas: A Case Study in Africa’ (2021) 10(1) Transnational Environmental Law, pp. 57-84.

33 Ibid., p. 61.

34 Ibid., pp. 63-4.

35 Ibid., p. 64.

36 Ibid., pp. 75-8.

37 Ibid., p. 78.

38 Ibid. 


\section{BROADENING THE BRANCHES: CRITIQUING STRUCTURES OF GOVERNANCE}

While transnational environmental law scholarship stimulates in-depth, localized case study analysis to better understand the multi-dimensional impacts of broader environmental problems, the literature also has a long-standing preoccupation with structures of environmental governance and their multi-layered manifestation in various environmental sectors. ${ }^{39}$ In the second set of contributions in this issue, Josh Martin, Guillaume Futhazar, Jona Razzaque and Claire Lester, and finally Kathleen Garnett and Geert Van Calster engage with the structure of environmental governance, tackling questions about pathways to, and participation in, environmental decision making. ${ }^{40}$

The study of environmental governance beyond the state is a particular strength of transnational environmental law scholarship. Emerging 'collaborative governance' and 'new governance' structures have developed in response to pressing broad-scale environmental concerns such as climate change, ${ }^{41}$ biodiversity loss, and protection of the marine environment. In 'Harnessing Local and Transnational Communities in the Global Protection of Underwater Cultural Heritage', ${ }^{42}$ Josh Martin expands the field of vision to include the protection of underwater cultural heritage $(\mathrm{UCH})$.

Martin explores the approach of 'community governance', understood as 'an increased governance by stakeholders and private actors operating at the local or at the transnational level'. ${ }^{43}$ Such an approach has the capacity to transcend the limits of conventional command-and-control, top-down regulatory approaches and marketbased regulation, ${ }^{44}$ and to provide various efficiencies and practical advantages, including enhanced compliance and enforcement. ${ }^{45}$ Community governance is argued to result in regulation that is more responsive and adaptive to community contexts, ${ }^{46}$ and capable of securing greater social legitimacy among stakeholders. ${ }^{47}$ Indeed, Martin suggests that it is now uncontroversial that communities - 'whether local or transnational, private or hybrid' - are capable of 'providing an essential force in delivering more effective environmental protection, including the protection of heritage sites'. ${ }^{48}$

Yet, Martin acknowledges that 'reliance upon communities to self-govern is not a panacea for global environmental governance'. 49 Top-down regulation still serves an important governance function. Public authorities 'act as facilitators or coordinators

39 J.L. Dunoff, 'Levels of Environmental Governance', in D. Bodansky, J. Brunnée \& E. Hey (eds), The Oxford Handbook of International Environmental Law (Oxford University Press, 2007), pp. 86-105.

41 A.J. Jordan et al., 'Emergence of Polycentric Climate Governance and Its Future Prospects' (2015) 5(11) Nature Climate Change, pp. 977-82.

42 Martin, n. 5 above.

43 Ibid., p. 87.

44 Ibid., pp. 89-90.

45 Ibid., p. 90.

46 Ibid., p. 91.

47 Ibid., pp. 91-2.

48 Ibid., p. 107.

49 Ibid., p. 93. 
of public-private effort, by enabling communities to self-govern or co-govern towards the achievement of wider public objectives' through the use of 'meta-regulation'.50 Various mechanisms - ranging from education, participation to secure community buy-in and community incentivization, especially through conveying ownership, to collaborative governance through inclusive systems of multi-party negotiation ${ }^{51}$ - have successfully contributed to effective community governance in the protection of UCH. As Martin concludes, community governance structures 'can serve to address many of the fragmentation, compliance, and public goods production weaknesses inherent in the existing legal systems that seek to protect UCH'. ${ }^{52}$

While Martin concentrates on the role of community actors in structures of environmental governance, the final three contributions in this issue look at the role of concepts or principles in environmental governance. Futhazar and Razzaque and Lester focus on the 'ecosystem approach' in international environmental law - a nascent governance principle which has received relatively little scholarly attention. Garnett and Van Calster discuss the concept of 'essential use' as an innovative regulatory approach in the control of hazardous substances.

Guillaume Futhazar's article on 'The Normative Nature of the Ecosystem Approach: A Mediterranean Case Study ${ }^{53}$ is directed towards an understudied aspect of the ecosystem approach (EcAp) - namely, its normative nature. ${ }^{54}$ Futhazar argues that the EcAp is best understood as an 'interstitial principle'. This argument is meticulously constructed through a combination of theoretical analysis and case study examination of two regimes implementing the EcAp in the Mediterranean: the Barcelona Convention $^{55}$ (focused on conservation) and the General Fisheries Commission for the Mediterranean (focused on the exploitation of natural resources). ${ }^{56}$

At the outset, Futhazar suggests that the EcAp can broadly be defined as 'requiring that the governance of ecosystems mirrors their interconnected and dynamic nature'. ${ }^{57}$ This involves three prerequisites for environmental governance: physical coherence (ecosystem governance should be conducted considering the entirety of the ecosystem); institutional coherence (instruments and institutions should be internally coherent); and adaptability (the governance framework should allow for change). ${ }^{58}$ With this definition outlined, Futhazar turns to the normative dimensions of the EcAp.

In general terms, jurisprudential scholarship asserts that principles serve the function of initiating and legitimizing rules, fostering their coherence, and assisting with their

50 Ibid., p. 94.

51 Ibid., pp. 98-107.

52 Ibid., p. 107.

53 Futhazar, n. 4 above.

54 Ibid., pp. 111-2.

55 Convention for the Protection of the Marine Environment and the Coastal Region of the Mediterranean, Barcelona (Spain), 16 Feb. 1976, in force 12 Feb. 1978, available at: https:/wedocs.unep.org/bitstream/ handle/20.500.11822/7096/BarcelonaConvention_Consolidated_eng.pdf? sequence=66\&isAllowed=y.

56 Futhazar, n. 4 above, pp. 116-7.

57 Ibid., p. 114.

58 Ibid., pp. 114-5. 
interpretation. ${ }^{59}$ However, principles can be either autonomous or interstitial. ${ }^{60}$ Futhazar argues that the EcAp is best understood as an 'interstitial principle'. $\mathrm{He}$ demonstrates that both in its general premise, and in its implementation in the Mediterranean region, the EcAp has been used as a tool for the legitimation, coherence, and interpretation of rules. ${ }^{61}$ Yet, it cannot function without the existence of other rules, unlike autonomous principles. ${ }^{62}$ This makes the EcAp similar to the (interstitial) principle of good faith in international environmental law, which is not a source of obligation in and of itself, and puts it in contrast with the (autonomous) prevention principle, which imposes a direct duty of due diligence on states. ${ }^{63}$

Theoretical analysis is not merely a matter of satisfying intellectual curiosity. It provides a way to explain and understand the world, and invites thinking about the way we should 'do' and 'live' international environmental law. As Futhazar concludes, the 'EcAp is not yet considered to be a source of international environmental law' ${ }^{64}$ Yet, its recognition 'could strengthen international environmental law as a whole' by fostering consideration of ecosystems in their entirety (for example, in environmental impact assessments) and by improving the overall design of international environmental law, ${ }^{65}$ which has been marked by its fragmented approach. ${ }^{66}$

In contrast to Futhazar, who primarily considers the normative dimensions of the EcAp, Jona Razzaque and Claire Lester, in their article 'Why Protect Ancient Woodland in the UK? Rethinking the Ecosystem Approach, ${ }^{67}$ focus on the application of the EcAp in practice. Their particular context for in-depth study is whether the EcAp is effective in the protection of ancient woodland under threat in the United Kingdom (UK). ${ }^{68}$ Environmental changes, such as the impacts of long-term climate change, can have severe and potentially irreversible effects on these ecosystems. ${ }^{69}$ Fragmentation of woodland obstructs pollination and leaves woods vulnerable to damage from adjacent lands, for example, from plots treated with pesticides. ${ }^{70}$ Non-native species and increased vulnerability to disease threaten the health of woodland. ${ }^{71}$ Private ownership also causes significant complications. ${ }^{72}$ These challenges, alongside poor management and uninformed decision making, can only be remedied, Razzaque and Lester argue,

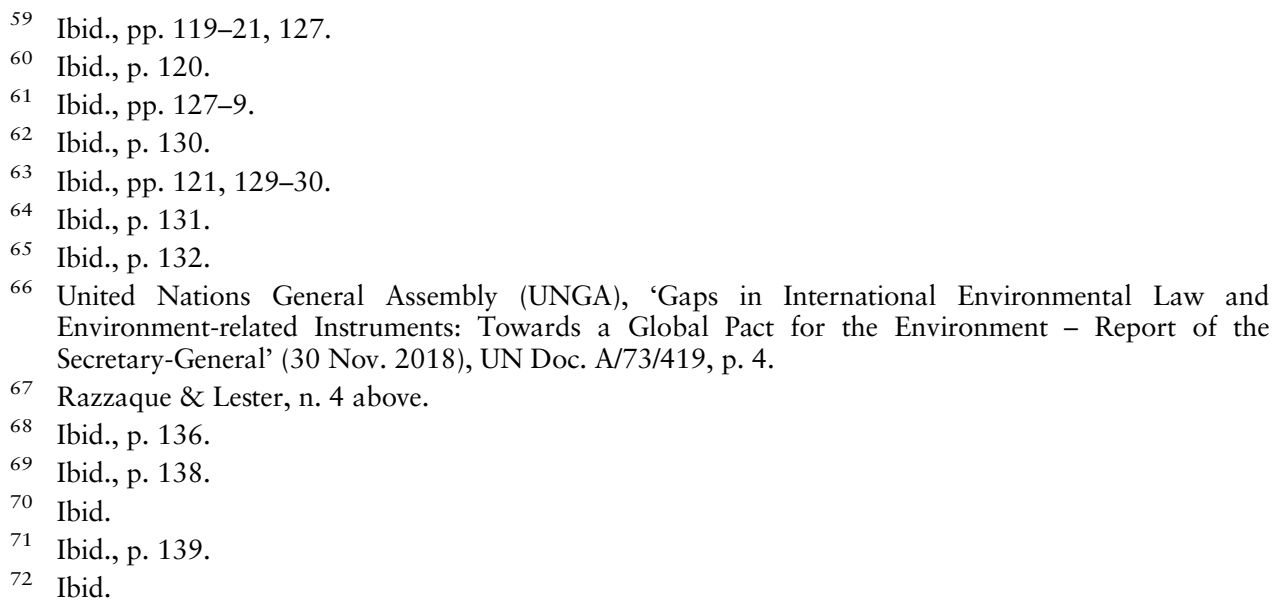


through 'acknowledging the (economic, societal, physical) context and viewing woodland for its multiple values, including intrinsic, instrumental, economic, and relational values' ${ }^{73}$

Razzaque and Lester contend that the EcAp can assist with recognizing the benefits and risks associated with integrating these values into decision making. The EcAp can be 'a conduit in taking into account the contribution of all stakeholders to better manage the land and maintain its functions and biodiversity'. ${ }^{74}$ Such principles draw attention to the integration of legal and management strategies, the balancing of conservation and sustainable use of biodiversity, cooperation between stakeholders, and negotiating of trade-offs between human and environmental priorities. $^{75}$

However, the authors demonstrate that, in practice, the EcAp 'remains an ambiguous and contested concept'. ${ }^{76}$ Legal and economic instruments in the UK, including law, policies and certification schemes, exhibit deep-seated anthropocentricity, which casts nature as 'capital' or a 'service provider' 77 According to Razzaque and Lester, what is needed to protect ancient woodland are stronger and specific laws integrating the EcAp approach, which recognize conflicts between different values and interests, including those of stakeholders, and promote an inclusive approach to reduce power asymmetries. $^{78}$

The final contribution to this issue, 'The Concept of Essential Use: A Novel Approach to Regulating Chemicals in the European Union' by Kathleen Garnett and Geert Van Calster, ${ }^{79}$ is an exploratory study into 'essential use' as an innovative regulatory approach to controlling hazardous substances. It neatly illustrates the diverse scholarship that a journal like TEL offers to its readers. Their article was prompted by a recent paper published in Environmental Science: Processes \& Impacts by Ian Cousins and co-authors, ${ }^{80}$ which called for per- and polyfluoroalkyl substances (PFAS, also known as persistent organic chemicals) to be regulated through the new concept of 'essential use'. ${ }^{81}$ Rather than to provide a commentary on the potential benefits or disadvantages of the concept of essential use, Garnett and Van Calster aim to inform readers 'how essential and non-essential uses differ from existing rules governing hazardous substances, and the potential impacts of the incorporation of these concepts into chemicals-related legislation'. ${ }^{82}$

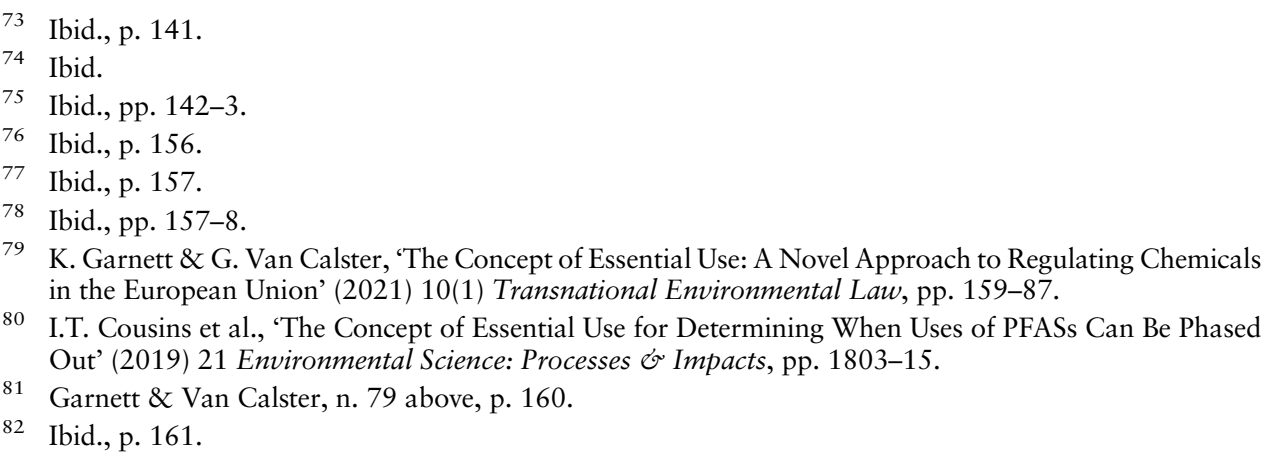


PFAS, or 'forever chemicals', present a difficult regulatory challenge. Not only are they highly mobile, persist in the environment for decades, and possess unknown human and environmental consequences, they are also numerous, with more than 4,700 PFAS in existence. ${ }^{83}$ As Garnett and Van Calster observe, given these features 'there is growing recognition that the [substance-by-substance] risk assessment approach to analyzing PFAS and their alternatives is neither efficient nor practical'. 84 The prevailing risk analysis and risk management approach to chemicals regulation in international, United States (US) and European Union (EU) law - which seeks to 'identify a limited number of a priori hazardous substances which require restriction, phasing out, or prohibition' - has been described by some as resulting in 'paralysis by analysis' ${ }^{85}$

In a clear departure from the risk management approach, Cousins and co-authors propose that environmental and public health would be better served if these substances were to be controlled by categorizing their function and use in society alongside the risk that they may pose' (essential use). ${ }^{86}$ The proposed essential use approach towards PFAS in downstream industries would place them in one of three categories: non-essential use (which triggers a phase-out or restriction); substitutable use (for products that serve essential functions but for which alternatives exist); or essential use (necessary for health, safety, or other important reasons). ${ }^{87}$

To date, Garnett and Van Calster find that the essential use approach has not been fully developed in treaties relating to international chemicals or EU law. Where it has been applied, it has been used as a derogation from the restrictions applicable to a priori hazardous substances, and remains predicated on a risk management approach. ${ }^{88}$ There remains, therefore, significant scope to embrace the concept of essential use in EU law, in particular, through legislative reform. Here, the references to essential use in the newly released EU Commission Chemicals Strategy for Sustainability ${ }^{89}$ may signal the way.

\section{CONCLUSION}

In its founding issue in April 2012, TEL's inaugural Editorial described transnational environmental law as concerned with neither 'a new, previously unknown layer of jurisdiction' nor a gathering and reconfiguration of 'legal principles and practices around a new substantive theme'. ${ }^{90}$ Rather, the connecting feature of such legal scholarship was

83 Ibid., p. 162.

84 Ibid., p. 163.

85 Ibid., p. 166.

86 Ibid., p. 163.

87 Ibid., pp. 166-7.

88 Ibid., pp. 181-2.

89 European Commission Communication, Chemical Chemicals Strategy for Sustainability: Towards a Toxic Free Environment, $\operatorname{COM}(2020)$ 667, 14 Oct. 2020. available at: https:/ec.europa.eu/environment/pdf/chemicals/2020/10/Strategy.pdf.

90 Heyvaert \& Etty, n. 3 above, p. 2. 
its role as 'a powerful new mode of understanding and engaging with environmental law' embodying a novel 'approach to legal studies and practice'. ${ }^{91}$

The articles in this issue provide a fitting illustration of TEL's vision, and of the value of transnational environmental law scholarship in advancing legal studies and practice. This vision has been expanded and developed in a truly remarkable ecosystem of work over the past decade.

As Editorial Board members of Transnational Environmental Law, we are, as always, deeply grateful to our many contributors, reviewers and Assistant Editors across the years for imbuing TEL's vision with such clarity and force, and to our evergrowing readership for their trust and support. We happily anticipate the milestone of completing and celebrating our first decennium at the end of this year, and already look forward to the next decade of Transnational Environmental Law.

Editors-in-Chief

Thijs Etty

Veerle Heyvaert

\author{
Editors \\ Cinnamon Carlarne \\ Bruce Huber \\ Jacqueline Peel \\ Josephine van Zeben
}

91 Ibid. 